\title{
Unfolding mapping practices: a new epistemology for cartography
}

\section{Rob Kitchin ${ }^{1}$, Justin Gleeson ${ }^{2}$ and Martin Dodge ${ }^{3}$}

In recent years there has been a turn within cartographic theory from a representational to a processual understanding of mapping. Maps have been re-conceptualised as mappings that ceaselessly unfold through contingent, citational, habitual, negotiated, reflexive and playful practices, embedded within relational contexts. In this paper, we explore what this rethinking means for cartographic epistemology, contending that attention needs to be focused on understanding cartography through the lens of practices - how mappings are (re)made in diverse ways (technically, socially, bodily, aesthetically and politically) by people within particular contexts and cultures as solutions to everyday tasks. We detail how these practices can be profitably examined using a suite of methods - genealogies, ethnographies, ethnomethodology, participant observation, observant participation and deconstruction - that are sensitive to capturing and distilling the unfolding and contextual nature of mapping. To illustrate our argument we narrate the unfolding production and consumption of a set of mappings of so-called 'ghost estates' in Ireland, a public geography project that has been covered over 300 times in local, national and international media and that has contributed to Irish public discourse and policy debates.

Key words cartography; epistemology; ontogenesis; practice; ghost estates; public geography

\footnotetext{
${ }^{1}$ NIRSA and Geography, National University of Ireland, Maynooth, County Kildare, Ireland

Email: rob.kitchin@nuim.ie

${ }^{2}$ NIRSA, National University of Ireland, Maynooth, County Kildare, Ireland

${ }^{3}$ Department of Geography, School of Environment and Development, University of Manchester, Manchester
}

Revised manuscript received 1 June 2012

\section{Introduction}

People have been thinking about and making maps for centuries. As conceptions and philosophies of space and scientific endeavour have developed, so too has how people have understood, measured and mapped the world (Kitchin et al. 2009). Consequently, there is a rich history of conceptual thought concerning the nature of maps and the art and science of cartography, with specific notions concerning ontology, epistemology, ideology, ethics, aesthetics and methodology shaping how maps are conceived, produced and used. Debates on the most productive way to theorise cartography have been particularly fruitful over the past half century, drawing on the philosophical literature in geography, psychology, language and semantics, and the philosophy of science (see Dodge et al. 2011). The most recent turn within cartographic theory has been a shift from a representational to post-representational and processual understandings of mapping, with attention focusing primarily on the ontological underpinnings of cartography (see Brown and Laurier 2005a; Crampton 2003; Del Casino and Hanna 2006; della Dora 2009; Kitchin and Dodge 2007; Pickles 2004; Wood and Fels 2008).

In this paper, we examine what a processual approach to cartography means for cartographic epistemology. We argue for a rethinking of the nature, approaches and methodologies of cartographic research, illustrating our argument with a real-world empirical example of mapping 'ghost estates' in Ireland in the wake of the global financial collapse of 2007. The paper builds on and extends previous research in which we argued for a fundamental re-conceptualisation of the ontology of cartography that rejected the ontological security of maps, instead advocating an ontogenetic position that understood maps as always in the process of becoming (Kitchin and Dodge 2007). In that research, we detailed that cartography traditionally consisted of a set of ontic knowledges, wherein the science of mapping advances within an ontological secure framework in which there is a taken-for-granted and unquestioned foundational ontology concerning how the world can be measured and meaningfully represented (Crampton 2003). Cartography's foundational ontology is that the world can be objectively known and faithfully mapped using scientific techniques that capture and display spatial information (as exemplified by texts such as Robinson et al. 1995). Cartography advances in these terms by asking self-referential, technical questions aimed at refining and improving how map representations are designed and communicate (focusing on issues such as accuracy, readability, interpretability, use of colour, scale, projection, data categorisation and symbology) in order to produce rules 
and standards regarding how spatial information is 'best' displayed, rather than by critically examining the ontological assumptions underpinning the notion of a map as a way of knowing and how it undertakes diverse work in the world.

As Crampton (2003) notes, whilst 'critical cartography' started to rethink some of the main philosophical underpinnings of cartography from the late 1980s onwards, much of its analysis implicitly accepted the ontical foundation of mapping, and as such the ontological status of maps remained secure. In the case of Harley's (1989) now classic analysis that recast maps as social constructions, for example, a map is unquestionably $a$ map in which there lies a representational truth of the world if only the ideology of its makers can be exposed and accounted for through deconstruction. Crampton thus concludes that Harley's analysis 'provided an epistemological avenue into the map, but still left open the question of the ontology of the map' $(2003,90)$. This ontological security is evident in other critical accounts of cartography, including those by Pickles (2004), Wood and Fels (2008) and Wood (2010), the result being that whilst 'the map might be seen as diverse, rhetorical, relational, multivocal and having effects in the world, [it] is nonetheless a coherent, stable product $-a$ map' (Kitchin and Dodge 2007, 333). Neither Pickles (2004) nor Wood and Fels (2008) believe there is in an inherent truth beyond the map and its construction, arguing that the map does not simply represent the world (a map is not a mirror, even one with an ideological veneer), but that it produces the world. Thus the map 'creates ideology, transforming the world into ideology' (Wood and Fels 2008, 7; original emphasis). In other words, maps are not representations but inscriptions (Pickles 2004) or a system of propositions (Wood and Fels 2008) - they capture something of the world whilst simultaneously doing work in the world; they precede and produce the territory they purportedly represent. And yet, whilst Pickles (2004) and Wood and Fels (2008) adopt antifoundational and non-representational approaches to understanding cartography, the map remains curiously static in these theorisations - it is resolutely $a$ map. Somewhat paradoxically then, the map remains ontologically secure at the same time that meaning and territory unfold through the work of the map (Kitchin 2008).

For us, if the use, meanings and the territorial referents of maps are conceived as fluid and ontogenetic in nature (always in the process of becoming), then it follows that maps are as well. Along with others, such as Del Casino and Hanna (2006), we have thus argued that maps possess no ontological security. Consequently, we have sought to rethink cartography through a processual, rather than representational, inscriptive or proscriptive, lens. ${ }^{1}$ Here, maps are conceived as being always of-the-moment, brought into being through practices (embodied, social, technical, political); that they are always in the process of mapping. As such, maps are never fully formed and their work is never complete. Maps are transitory and fleeting, being relational and context-dependent; their history and development contingent and non-progressive (Kitchin and Dodge 2007). They are always mappings; spatial practices enacted to solve relational problems (e.g. how best to create a cartographic representation of space, how to understand a geographic distribution, how to get between $\mathrm{A}$ and $\mathrm{B}$, and so on). Mappings must never then be assumed to have innate ontological security, instead they are brought into being and made to do work in the world (e.g. inscribing territory, shaping discourse, producing knowledge, informing and framing decisionmaking) through practices such as drawing, interpreting, translating, communicating, determining, denying and so on. These mapping practices give mappings the semblance of being 'immutable mobiles' (stable and transferable forms of knowledge that allows them to be easily transferable across space and time; Latour 1987) with ontological security, because they are learned and constantly reaffirmed. Mappings, however, do not appear and emerge in the same way for all individuals. Rather they unfold in context through a mix of creative, reflexive, playful, affective and habitual practices; affected by the knowledge, experience and skill of the individual to perform mappings and apply them in the world. Table I summarises the difference between the ontological positions of Arthur Robinson (what one might label as traditional scientific cartography) and three versions of 'critical cartography' - Harley (1989), Kitchin and Dodge (2007) and Wood and Fels (2008).

\section{Rethinking the epistemology of cartography}

Rethinking cartography through an ontogenetic lens inevitably leads to the need to reconsider cartographic epistemology. From our perspective, such a reconsideration necessitates a radical shift, as the conceptual bases of cartography move from being concerned with the 'rules' of map design, and techniques of cartographic production, and/or documenting and deconstructing the underlying ideologies and agendas of maps, to a processural perspective concerned with how mappings and cartographic design, technique and ideology emerge time and again through a plethora of practices framed within a complex discursive and material context, and the diverse, unfolding work of mappings in the world. For Brown and Laurier (2005a, 23), this necessitates a change in approach 
Table I The key characteristics of different ontologies of cartography (adapted from Kitchin 2008)

\begin{tabular}{|c|c|c|c|}
\hline Robinson (1952) & Harley (1989) & Wood and Fels (2008) & Kitchin and Dodge (2007) \\
\hline Maps as truth & Maps as social constructions & Maps as propositions & Mappings \\
\hline $\begin{array}{l}\text { Representation } \\
\text { (descriptive) }\end{array}$ & Representation (descriptive) & Inscription (prescriptive) & $\begin{array}{l}\text { Practices } \\
\text { (relationally prescriptive) }\end{array}$ \\
\hline Essentialist & Constructed & Constructed & Emergent \\
\hline $\begin{array}{l}\text { Map ontologically } \\
\text { secure (fully } \\
\text { formed/immutable) }\end{array}$ & $\begin{array}{l}\text { Map ontologically secure } \\
\text { (fully formed/immutable) }\end{array}$ & $\begin{array}{l}\text { Map ontologically secure } \\
\text { (fully formed/immutable; } \\
\text { meaning mutable) }\end{array}$ & $\begin{array}{l}\text { Mapping ontologically insecure } \\
\text { (emergent and mutable) }\end{array}$ \\
\hline $\begin{array}{l}\text { Inherent, objective truth; } \\
\text { non-ideological }\end{array}$ & $\begin{array}{l}\text { Inherent truth; } \\
\text { ideological mask that can } \\
\text { be removed by deconstruction }\end{array}$ & Map ideologically loaded & $\begin{array}{l}\text { Ideology emergent and relational } \\
\text { to context }\end{array}$ \\
\hline
\end{tabular}

from 'imagined scenarios, controlled experiments or retrospective accounts' to examine how mappings emerge as solutions to relational problems. In other words, the kinds of questions asked, and how they are asked, change quite substantially. This is not to say, however, that technical questions disappear, but rather that they are recognised as being contingent, relational, contested and context-dependent; and that addressing technical questions is in itself a process of seeking to solve a set of relational problems. Accordingly, Ingold (2010) contends that this means adopting an epistemological approach that seeks to follow the 'lines of becoming', tracing out how mappings unfold in the entangled meshwork (conditions of possibility among the relations between actants) of their creation, use and unfolding of everyday life and space.

Clearly, following the diverse ways in which mappings emerge is a large and complex undertaking, potentially involving many different stages, sequences and scenarios, stretched out across multiple sites and scales. For example, one could consider the generation of specific geospatial data, framed within technical, legal, fiscal, social and political contexts, and shaped by the limitations of institutional access and recording devices, and the interpersonal relations of people involved. Or one could focus on the iterative and citational production of a mapping - how a mapping emerges through multiple drafts shaped by skills, experience, shared discussion and debate, the limits of technical knowledge or equipment or the vagaries of the software and display media being used (which are encumbered with 'default settings' - some overt and some covert), and is framed by its supposed intended purpose, the ideology of its initiators, and so on. Or one could examine the ways in which particular mappings form part of the solution to relational problems such as finding a required location, browsing a landscape, navigating a route or displaying a spatial pattern, and how these mappings emerge in multiple, contingent ways shaped by knowledge and skills, wider context and how these mappings lead to diverse and contested outcomes. Or one could explore the entire complex discursive and material assemblage and its interactions that shape a mapping's genesis and unfolding: knowledges (existing artefacts, books, papers, manuals, magazines, mailinglists, conferences, gossip), forms of governmentalities (data and metadata standards, file formats, protocols, intellectual property regimes), practices (ways of doing, aesthetic choices, design conventions, personal idiosyncrasies and ignorance, office routines and cultural norms), subjectivities (relating to cartographers, sellers, users), materialities (paper, pens, technical equipment, screens, software, public displays) and organisations (corporations, professional societies, retailers, government agencies, universities, local authorities). Or one could try and consider these aspects in conversation with each other, in effect seeking to chart the workings and work of a mapping from data generation through to its multiple 'lives' in the world.

The latter is no easy task, especially as it is impossible to observe or make sense of all the reinscriptions and re-territorisations of most mappings. For example, MasterMap, a cartographic database produced by the Ordnance Survey (UK), is constantly in the process of being updated through the generation and inclusion of new data and involves dozens of workers with varying skills, personal experience, tacit knowledge; and all kinds of equipment and software, and different sites and spaces of activity. The mapping data are processed with respect to bundles of procedures, conventions, standards, intellectual property regimes, built upon generations of established cartographic practices that provide certain path dependencies that are endlessly cited. Once displayed on a screen or printed onto paper, the mapping makes its way into the lives of potentially hundreds of thousands of people, who beckon it into being to try and solve millions of different relational problems, re-inscribing the world in all kinds of ways. 
In recent years, a small number of scholarly studies have started to develop an epistemology for understanding how mappings emerge, circulate and do work in the world, and detail methods suitable for capturing how mapping unfolds. Brown and Laurier's (2005a) study used video-based ethnography to examine how maps are enrolled in the process of everyday navigation while driving between locations. Their work highlighted that a particular mapping representation is entangled within cultures of practice and affect, and how a mapping, journey and the social interaction within the car between passengers and driver emerged through each other in contingent and relational ways within the context of the trip. That is, there is a complex interplay occurring between driver, passengers and the mapping, including conversations about the mapping, placing of the present location onto the mapping, placing the mapping into the present location (and being on-the-map-on-the-move), using the mapping to make (imperfect but workable) decisions about which way to travel (where to turn, possible short-cuts, places to park, etc.), shaped by the context of earlier trips, the experience of the current journey and interpersonal relationships. In a related study of tourist engagement with mappings, Brown and Laurier (2005b) argued that mappings are rarely employed in isolation to solve a task - rather they are used in relation to other sorts of information such as street signs, landmarks or descriptive narrative in a guidebook or are invoked through a collaborative reading in conjunction with companions or perhaps enquiries to strangers. In other words, a mapping is often produced and read as a collaborative artefact and emerges through an unfolding set of practices and context.

Del Casino and Hanna (2006) examined how visitors' interactions with the historic town of Fredericksburg in Virginia were shaped by an active engagement with genre tourist mappings, along with other promotional texts and narratives (such as a guided tour) through a set of in-depth interviews and detailed participant observation. What they demonstrated was that the tourist mappings were used to beckon into being new understandings of the town, but that simultaneously the interaction with the locale was read back into the process of map-making, rendering it more legible. Tourists, they concluded, are always consumers and producers of mapping, beneficially enrolled as authors and readers of cartographic texts. Meaning emerges through action and the on-going understanding of space is shaped by meaning in a complex, recursive and intertextual performativity. The tourist mapping of Fredericksburg then is never a finished map, but is always a mobile mapping, continually being crafted by tourists and in turn co-producing the Fredericksburg that they encounter and remember.
Brown and Knopp (2008) discuss in some depth their attempts to reconcile the ontological and epistemological position of queer geographies, which rejects the totalising certainties and essentialising tendencies of traditional cartography, with the wish to produce a mapping of gay and lesbian life in Seattle over several decades and that adequately represented the memories of a diverse set of contributors. Their solution was to embrace the notion of colliding epistemologies - tacking back and forth between a queer theoretical framework and the more conventionally scientific strictures of cartography to produce a mapping that looks like a conventional map, but that was produced through a contested, negotiated, multi-vocal process. They detail an ethnography of this process, recounting the intricacies of the various steps through which they progressed to formalise a mapping that was sensitive to the politics of the community it sought to represent and that openly acknowledged the contested set of practices and knowledges that led to its creation, and was aware of the diverse ways in which it would be engaged with on publication.

Through an extensive set of eight case studies focused on the production of nature, Wood and Fels (2008) detail how maps are constructed and work as systems of propositions. To operationalise their analysis they turn to cognitive linguistics to rethink map design as 'cognitive cartographics'. Cognitive linguistics examines the ways that words activate neural assemblages and open up 'thinking spaces' in the mind within which meaning is constructed by linking present information with past knowledge. Wood and Fels (2008) contend that maps perform like words, likewise firing-up thinking spaces. Applying 'cognitive cartographics', they argue, enables a non-representational approach to map design and map reading focused on meaning construction and not graphic design and the nature of signs. The empirical approach is to deconstruct how maps work as postings; how the nature of maps (is - category) and the nature of maps (there - sign) conjoin to create a unified spatial ontology (this/there) and examine a map's 'paramap', that is the conjunction of its 'perimap' (the production surrounding a mapping - design, title, legend, scale, cartouches, etc.) and 'epimap' (the discourses circulating a map designed to shape its reception - advertisements, letters to reviewers, endorsements, lectures, articles, etc.).

Della Dora (2009) moves beyond a conventional reading of atlases as a collection of visual representations, instead examining the performative and social, visual and tactile, encounters between atlases and their users. Her analysis of three different atlases conceptualises them as 'memory theatres' engaged with through an embodied performativity; the repetition of ordinary acts such as tracing with a finger and visual 
scanning that evoke and create memories of mappings and places. She argues that an atlas does work in the world through physical and imaginative encounters with its materiality - 'a two-way conversation that is at once visual and tactile' $(2009,243)$ - that enables meditative and memorisation practices to take place ('gazing, pointing, leafing through, collecting, colouring, annotating;; 2009, 249). Such encounters, she argues, beckons the atlas and the multiple mappings contained within into being; into a continuous state of becoming; of inscription and re-inscription, assembly and re-assembly. In turn, she argues, that understanding maps as fluid objects recasts the 'history of cartography as a history of interactions and co-authorships between map-makers and map-users' (2009, 240). Such a particularistic history provides a rich alternative reading to rather monolithic, teleological and sometimes heroic accounts of scientific 'advances' in cartography that typically wash out the complex contingencies and embodied materialities of mapping production and use.

Gregory's (2010) recent work critically interrogates the ways in which digital mappings played an intrinsic part of the US military's counterinsurgency and occupation strategy in Iraq. Conceptualising maps as events, Gregory provides a genealogy of how such mappings were beckoned into being in conjunction with particular geopolitical and biopolitical imaginaries as supposed 'truths' and made to do deadly work in the world justifying and asserting the US's command of the so-called 'battle space' of Baghdad and other Iraqi cities. In particular, Gregory shows how the mappings crafted by the US Army recognised the unfolding, mutable and transient nature of everyday life by trying to monitor, in near real-time, what was happening in the city. These were mappings literally beckoned into being in the moment, here and then gone, but nonetheless utilised to produce a powerful discourse and in directing on-the-ground realities for soldiers and civilians, including the targeting of attacks. And yet, as much as these mappings sought to perform a 'god's eye' trick, the gaps and fissures in their underlying data were exposed by insurgency that proved difficult to capture and monitor, and the messiness of everyday life that was difficult to cartographically order despite vast technical resources.

\section{Methods to understand unfolding practices of mappings}

The studies detailed above used a number of methods to capture and distil the unfolding and contextual craft of mapping. They include the production of genealogies and ethnographies, ethnomethodology, participant observation, observant participation and deconstruction. Such qualitative methodologies are relatively rarely used in conventional cartographic research, which in its evaluation of production and visualisations or map communication mostly employ quantitative methods, often from the psychologists' toolkit. The epistemological approach in which these more conventional methods are employed is underpinned by an ontological framework in which mappings are stable, knowable, essential outputs, and as such these methods are not well suited to either expose or capture the subtle, diverse ways in which mapping unfolds. Much critical cartography, on the other hand, has been limited largely to the method of textual and linguistic deconstruction, for the most part ignoring other methodological approaches.

A genealogical method is most often used to trace out the contingent unfolding of a system of thought or set of actions over time, rather than producing a rational, teleological historiography (see Crowley 2009). As such, a genealogy seeks to untangle and make sense historically of the multiple, complex and sometimes contradictory or paradoxical iterations of mapping projects - the evolving and situated unfolding of ideas, decisions, constraints, actions and actors that shaped their development, along with dead-ends and apparent failures. It can identify points of confluence when people or ideas come together and give rise to new mappings. Through such an analysis, we can start to trace out over time the ways in which spatial data becomes codified in mapping form, and how the mappings produced do work in the world. The production of such genealogies can work across different scales and times. They show how the future is built upon the past, but is not necessarily determined by it in simple cause-effect ways. For example, it may consist of a genealogy of the production of a single mapping or mapping system, tracing out its development from initial idea, its various material forms, its places of deployment and iterative changes within a particular historical period, and the various inter-connections between ideas, technologies and actors. At a larger scale it can trace the development of forms and uses of mapping over a longer period or a wider system of power-knowledge (see Edney 1993; Gregory 2010).

Ethnographic studies provide immersive and holistic analyses of social phenomena by describing in detail the many relations between multiple actors and the material world they occupy (Herbert 2000). Empirical material is usually generated by participant observation undertaken over an extended period of time (several months or more) and in-depth interviews with a wide range of stakeholders, complemented by other techniques such as a hermeneutic reading of related documents and artefacts (such as manuals, email exchanges, visual materials, work spaces, etc.) and time-diaries. In essence, ethnography seeks a nuanced understanding of the lifeworld of a 
community - its social relations, its rhythms, its cultural meanings, its patterns of power and decisionmaking, ways of being and so on - in order to comprehend how it is constituted and continuously unfolds. The researcher goes beyond surface descriptions (what is happening) and gains understanding of why it is happening by being part of the relations and practices being studied. Ethnographic studies would provide rich, holistic accounts about the nature of map-making as a messy, emergent process, rather than the idealised sequence set out in most cartography textbooks.

In addition, there needs to be further use of ethnomethodology in mapping studies as initiated by Brown and Laurier (2005a 2005b); that is, a systematic charting of the practices that people employ to undertake cartographic activities such as mapping creation and use. Such studies would focus on detailing the vernacular use and everyday practices of mapping systems and tools (e.g. egocentric mapping using satnav gadgets, personalised online mappings such as property searching or real-time mapping updates related to road traffic), and would reveal how technologies are routinely enrolled by people to solve problems they face, instead of how the systems have been designed to work. Studies would necessarily be small-scale and focused, rather than generalist in nature. This kind of research could usefully study incomplete and failed mapping practices (e.g. getting behind the scare stories of satnav 'blunders') to reveal social contexts and the embodied experience of spatial problem-solving using maps and other relevant information sources. A pragmatic end goal of such local field studies would be to reconstruct the conditions under which mapping is deployed, so as to help in the design of future mapping systems.

Observant participation is a kind of self-ethnography, wherein a researcher undertakes sustained examination of their own and other people's engagement with a phenomenon or practice (Crang and Cook 2007; Morton 2005). In this case, it would consist of a self-ethnography of the unfolding action of creating and using mappings. This is inherently a selfreflexive exercise, one that is subjective and personal, in which the researcher strives to rigorously examine their own practices in a field in which they are a key player, charting the ways in which their research, and the reaction to that research, unfolds. The principal benefit of such an approach is that the researcher is fully aware of the diverse and complex landscape (socially, politically, economically) within which a mapping emerges; they were the ones after all creating the mapping, experiencing various negotiations with other actors, playing with the data, using various pieces of software, making decisions, reacting to certain constraints and situations, and to varying degrees dealing with the on-going life of a mapping once it is released for others to engage.

Deconstruction is a method of analysis that seeks to tease apart and reveal meaning within texts broadly conceived (pictures, mappings, writing, speech). Texts are understood to be mediators of a message and through forensic examination of their deeper meanings can be revealed and understood. In essence, deconstruction looks beyond surface signs and face values to challenge the taken-for-granted readings of a text in order to open up the hidden, or tangle up the overly simple, meanings within that text (Burman and MacLure 2005; Harley 1989). It is a critical reading that uses techniques like displacing assumed meaning or power, identifying points of paradox or contradiction, untangling inter-textuality and embedding within wider materialities and contexts, and reflecting on the positionality of the speaker and their intended audience (Burman and MacLure 2005). Deconstruction has been a key method within critical cartography for understanding mappings within the wider context of their production, circulation and application, revealing the meanings, ideology and power inherent within their design, focus and presentation (Harley 1989). Importantly for us, deconstruction does not have to be constricted to the materiality of mappings alone, but the same techniques can be used to open up or entangle the practices of mapping.

\section{An unfolding mapping: the 'ghost estates' of bankrupt Ireland}

To illustrate the potential of our suggested set of new epistemological and methodological strategies to understand the unfolding nature of cartography, in the remainder of the paper we provide an example based on the mapping practices of two of the authors in an academic context. In unanticipated and unplanned ways, the mappings subsequently circulated widely through Irish polity and were a key component in debates in local, national and international newspapers, radio and television, and contributed to the creation of a new government programme in Ireland. To do so, we present a genealogy of the mapping project drawing upon observant participation of the unfolding processes. The example we concentrate on is the mapping of unfinished housing schemes in Ireland, the so-called 'ghost estates' phenomena.

Unfinished estates are new residential developments of two or more units that have low levels of occupancy and/or are under construction. As of October 2011 there were 2876 unfinished estates in Ireland identified by a Department of Environment, Community and Local Government (DECLG) survey, containing 122048 housing units (36 510 of which are 
vacant or under construction). Of these estates, 2066 have either unfinished units or incomplete roads, paths, lighting or sewage works, and of these 1822 are inactive (no development work is taking place). These estates litter the post-'Celtic Tiger' Irish landscape, the visible legacy of significant over-building in the years immediately before and after the global financial crisis of 2007. Indeed, the housing and commercial property bubble in Ireland is one of the principle reasons that its recession and bank bailout has been deeper and more costly than almost any other EU country (Kitchin et al. 2012). At the end of 2011 there were 294202 vacant residential properties $(14.7 \%$ of stock) (CSO 2011a), while house prices had fallen on average by between 43 and 58 per cent across the country (CSO 2011b); between one third and one half of all mortgages were in negative equity, and over 8 per cent of mortgages were more than 3 months in arrears (Central Bank 2011). Some 23 per cent of office space in Dublin was vacant in Q2 2010 (Savills 2010). In addition, 448600 people were on the Live Register (claiming some form of work-related welfare), with 14.5 per cent of the working-age population officially classed as unemployed, up from 4.5 per cent before the crash (CSO 2011c). Between 2007 and 2010, Irish GNP had fallen in total by 21.5 per cent (CSO 2011d). Having already bailed out the banks and established NAMA (the National Assets Management Agency) that bought property loans from the banks at a haircut price, in November 2010 the country was forced to accept an IMF-EU-ECB finance package to avoid a sovereign debt default. Unlike other countries, whose banking crisis was triggered by their banks' exposure to various financial derivatives of US sub-prime loans, Ireland's crisis was almost entirely self-created through the excessive and risky lending of banks to developers for speculative building in a bubble market (Honohan 2010; Kitchin et al. 2010 2012). Unfinished estates, given their manifest presence in the landscape, have now become emblematic of the larger Irish economic depression.

\section{Emerging context}

Our interest in unfinished housing estates emerged out of three endeavours. The first was our own personal curiosity with respect to the new phenomenon, widely visible when one drove around Ireland. This led the first author to make planning and property a central theme of the novel he was working on, which in turn led to the undertaking of background research on housing development and the planning system. The second was the research institute in which two of the authors work (National Institute of Regional and Spatial Analysis; NIRSA) had started to look at housing data with a view to creating an all-island, annual housing report similar to the State of the Nation housing overview produced by Harvard University for the US. ${ }^{2}$ We had been systematically trawling different data repositories to document what housing information did exist, their utility, and the potential for spatial analysis and cartographic depiction at a county scale or more localised scale. Third, in response to the banking crisis, in November 2009, several academic geographers from across the Irish university system came together for a one-day symposium held in National University of Ireland Maynooth, titled 'Geography After NAMA'. The event sought on the one hand to discuss how the financial crisis was playing out from local to international scales, and on the other to consider how geography and the social sciences more broadly might respond to the crisis in productive ways. One significant outcome of that event was to establish a public geographies project centred on blogging that would provide informed commentary, data analysis and interpretation about the crisis and how it was playing out geographically. ${ }^{3}$

These three entry points complemented one another. We were becoming increasingly interested in the housing crisis with respect to assessing the extent of the issue and understanding the policies and processes that had led to such a situation from both a personal and professional perspective, with an active interest in blogging the results of on-going geographic research and interpretation. For one blog post, we decided that it would be interesting to try and document the extent of the 'ghost estate' phenomena in order to be able to contribute to growing public and media debates over the objectives and operation of NAMA, the assets it was buying and their long-term economic value given the condition of the housing market. What was clear to us through our initial research was that very little was publicly known about the post-crash residential housing market in Ireland with respect to stock, availability and pricing due to the fact that published property statistics were limited in scope (there is no disaggregated house price data, housing stock data are only generated every 5 years through the national census, and stamp duty and land registry data were considered to be private information and consequently were not publicly available); moreover, what public data there were available were poorly analysed and not spatially interpreted.

\section{Unfolding mapping of 'ghost estates'}

The first 'ghost estates' mapping unfolded between mid-December 2009 and late January 2010. Initially, under the direction of the first author, the second author in collaboration with a colleague decided to try and document the extent of the 'ghost estate' issue, and to determine if there was a distinct geographical pattern by producing a mapping of their locations. At that time, whilst the phenomena of 


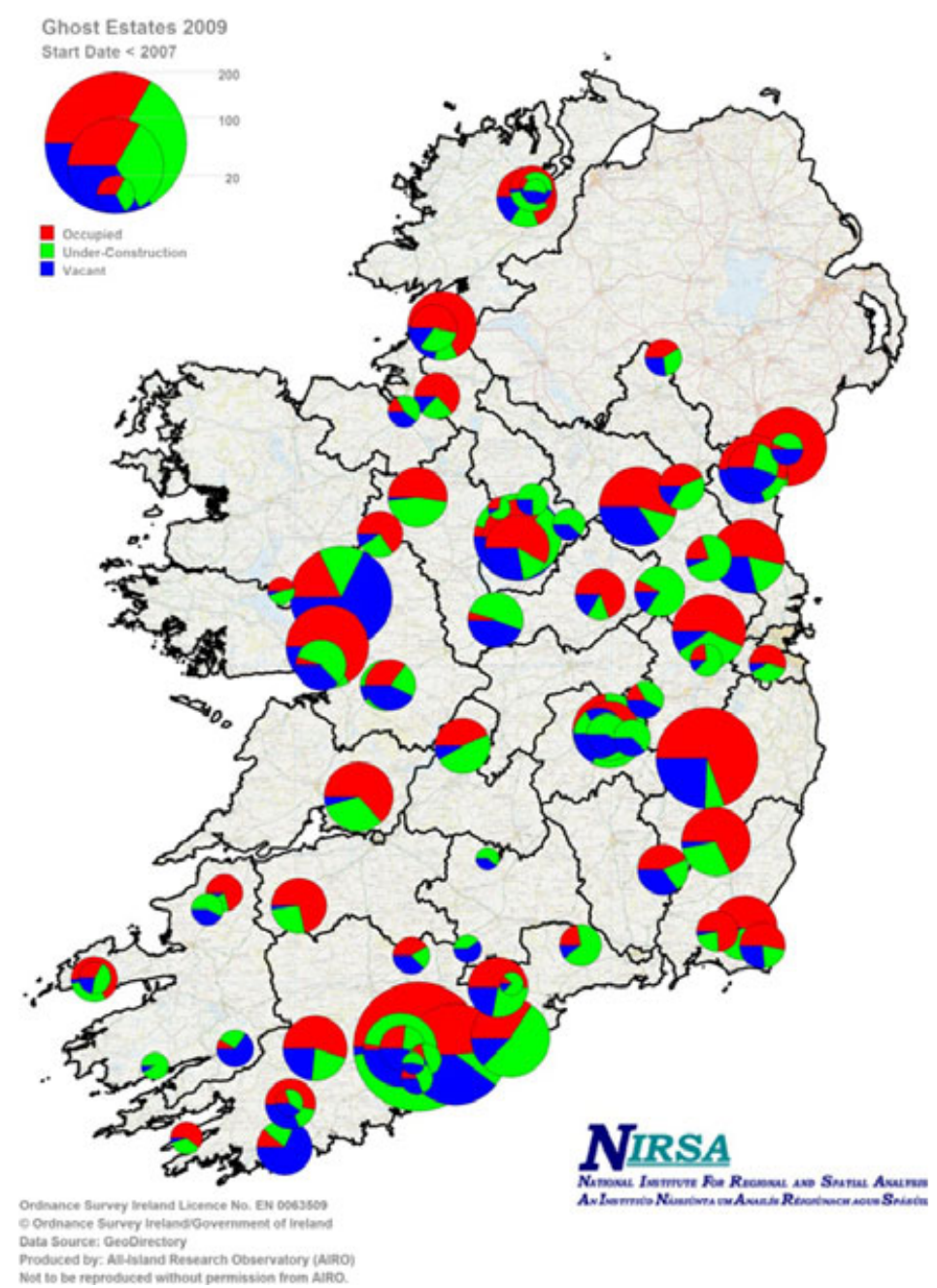

Figure 1 Spatial distribution of under-construction 'ghost estates', 2009

unfinished housing schemes was being discussed in the media, the analysis lacked a firm evidence base as to the extent and distribution of 'ghost estates' and the number of units on them. The result was that the debate remained at the level of anecdote, and yet, the state was risking huge amounts of taxpayers' money (at the time estimated $€ 54 \mathrm{bn}$, later reduced to $€ 32 \mathrm{bn})$ to buy a vast quantity of so-called 'toxic assets' (originally worth $€ 77 \mathrm{bn}$ ) through NAMA.

What was known was that such 'ghost estates' had been built across the country, many of them unfinished and yet often had households living on them. Based on our experience of using various Irish spatial and demographic data sets, it was decided to explore the use of Geodirectory (a commercial product constructed by An Post, the national postal service, and Ordnance Survey Ireland, the state mapping agency), which records details on all the nation's properties as a means to identify 'ghost estates'. Geodirectory is only available for use under licence and its availability to the public or academic community is limited because it requires specialist knowledge and its annual licence is expensive.

What followed was a series of conversations between the researchers discussing how to proceed, including the appropriate technical parameters for identifying 'ghost estates' and what kind of housing we were most interested in, accompanied by an exploration of the Geodirectory database and a scoping exercise to see if meaningful data could be extracted. These practices of conversations, explorations and scoping were tentative 'brainstorming' sessions, where ideas were thrown out, picked up, debated, run with, dropped, reworked, re-examined and assessed; 
possible methods were tried, tested, tweaked and abandoned. How they unfolded was contingent and relational, undoubtedly shaped by experience, knowledge, discussion, happenstance, play, intuition and so on. At the end of the process we had a customwritten software tool that 'data-mined' the Geodirectory database to identify all housing estates that had been under construction for 2 years or more, where 25 per cent of houses were flagged as unoccupied or under construction. The resulting dataset was then thoroughly examined for flaws or errors and tidied up, including an initial mapping of the data. Based on this initial on-screen cartographic depiction, we had another discussion, re-examining the process and the mapping, and changed the vacancy/under-construction parameter from 25 per cent to 30 per cent and also changed some of the design features of the mapping (see Figure 1). A number of the identified 'ghost estates' in Dublin and Kildare were then visited in person to check the validity of the method and data, taking photographs of the sites. The mapping with accompanying interpretative text was published on the IrelandAfterNAMA blog on 12 January $2010 .{ }^{4}$ This initial mapping was undoubtedly the result of a complex, messy, negotiated, unfolding process of construction, evolving out of a series of encounters and iterative research steps. There was no teleological inevitably about its production or form, but rather it emerged through a negotiated process mediated by the skills and knowledge of its creators, and the settings of the mapping software.

\section{A mapping at work in the world}

Once published, the mapping then started a new life. Given that we felt that the mapping would be of public interest, we emailed a copy of the blog entry to a number of newspapers, but the story was not immediately picked up and blog post itself received relatively few hits in comparison with other posts. The Sunday Times (Irish edition) carried a piece on Sunday 17 January, though disappointingly it did not include the mapping (The Sunday Times, 2010). Here, the mapping was sufficiently interesting to draw attention to the issue, but was not deemed rhetorically powerful enough for publication (where it would have displaced a large amount of text). In other words, the journalist chose to focus on the epimapping, in Wood and Fels' (2008) terms (the accompanying narrative), rather than the mapping itself. Nonetheless, the mapping (the mapping plus paramapping) had succeeded in enticing the journalist to engage with the story. The next day we made two decisions. Firstly, to produce a mapping of all the 'ghost estates' in Ireland started since 2005, regardless of whether anybody was living on them or the length of time under construction to try and determine the full extent of the phe- nomenon. Second, to provide contextualisation for the mapping, we calculated the total number of vacant houses in the country. ${ }^{5}$ We completed the second task first and wrote a short blog post outlining our analysis and published it on the Monday morning. ${ }^{6}$ We did not think the figure or the proof would be particularly controversial given the 2006 census data regarding housing vacancy levels and general, public knowledge that the building boom had continued well into 2008.

By Tuesday afternoon, however, the media had discovered our post, aided by the university's PR company, and the story was the third item on the national television news (including an interview with the first author outside of government buildings). The following day the story was covered in the newspapers and the first author appeared on national and local radio programmes. We were also contacted by television current affairs programmes and documentary-makers. Here were some data, which we had produced to complement and contextualise our mapping analysis, that seemingly gave some indication of the size of the housing market oversupply and the scale of the problem facing Ireland. Moreover, our estimate contrasted markedly with an announcement by the then Minister for Housing, Michael Finneran TD, that the oversupply was much lower at 100-140 000 housing units, made unbeknownst to us on the same morning as our blog post. In fact, our estimate was of vacancy not potential oversupply, and so the comparison was void and we spent much time trying to correct this conflation. Immediately, vested interest groups such as the Construction Industry Federation (CIF) and large estate agent companies sought to counteract our analysis, and it was at this time we received our first irate phone call accusing us of trying to 'destroy' a housing market recovery. During the rest of the week we blogged more analysis, reacting to criticisms and providing a longer explanation of our vacancy estimate, and calculated individual county rates and a housing model of potential oversupply (using a different method to the Department of Environment, Community and Local Government, but coming to roughly the same overall figures ${ }^{7}$ ). We also continued to work on the 'ghost estates' mapping, producing a new 'uncleaned' mapping. We then presented this mapping in a paper at the 'Planning for Economy Recovery' conference (21-22 January 2010) in Enniskillen, attended by government and local authority officials, to little reaction beyond curiosity.

\section{New unfoldings}

On Monday 25 January 2010, the first author was due to appear on Frontline, an hour-long, live current affairs television debate in Ireland, with a representative of the CIF and the Housing Minister. The 
Post 2005 Ghost Estates of more than 10 houses with greater than $50 \%$ Vacancy/Under-Construction

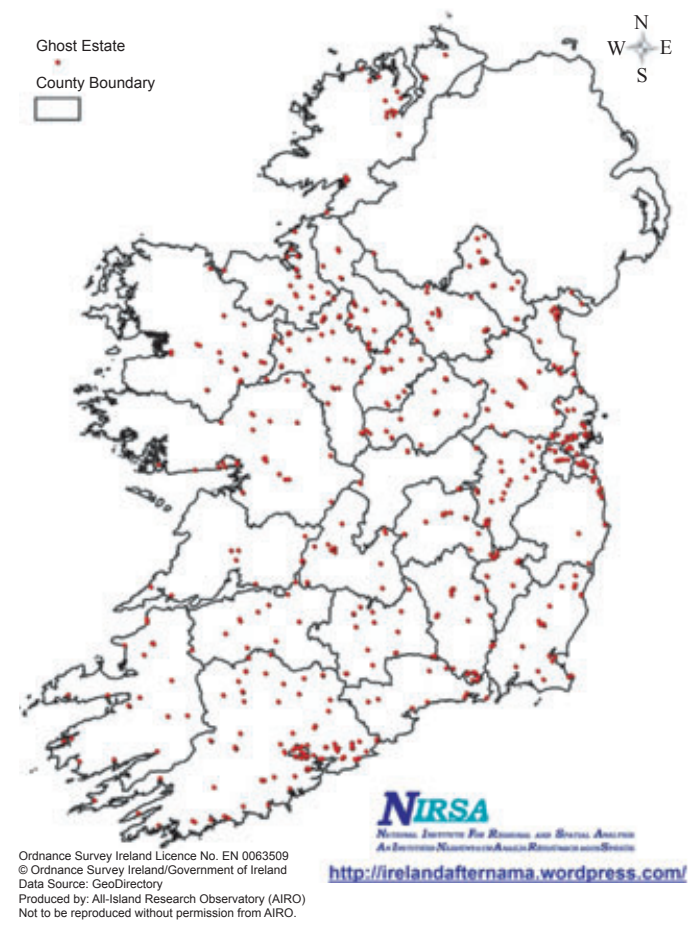

Post 2005 Ghost Estates of more than 10 houses with greater than $50 \%$ Vacancy/Under-Construction

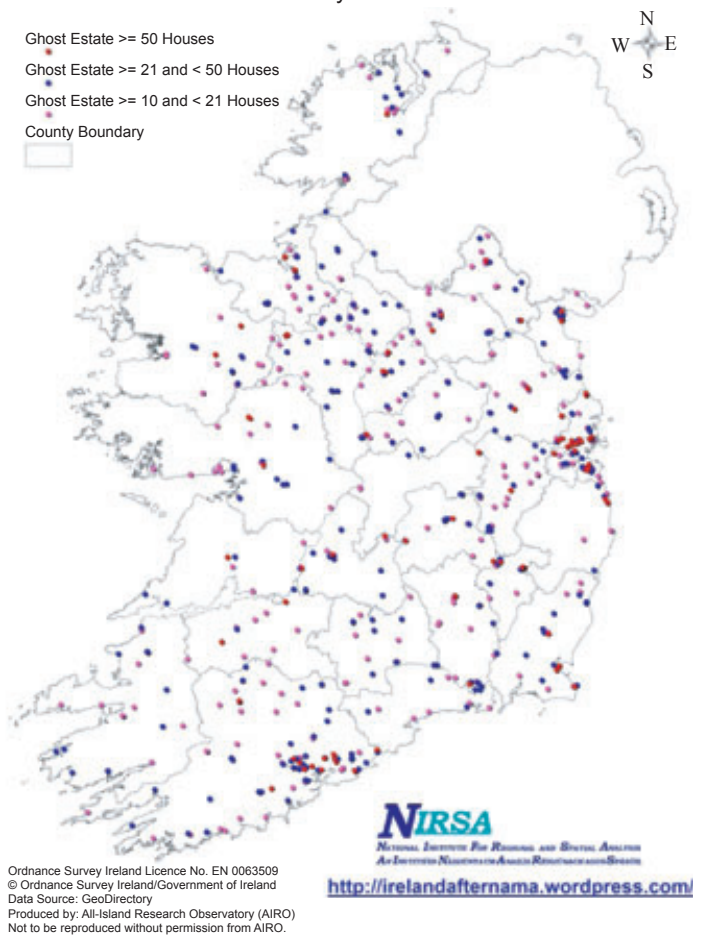

Figure 2 'Ghost estates' in Ireland (released iterations 1 and 2)

programme's producers knew we were working on a new 'ghost estate' mapping and asked for an exclusive to show the results, with the mapping published on the IrelandAfterNAMA blog at the time of broadcast. The day was spent cleaning the data and doing multiple, detailed error checks, refining the mapping design, and involved a whole series of conversations about the data and their mapping, which went through several iterations. MapInfo was used to construct the mapping and this software shaped to an extent, in a contingent fashion, the 'look and feel' of its outputs due to the way in which cartographic conventions are built into its algorithms and the options available to its users. In order to counter potential criticism about the definition of a 'ghost estate', we tightened the initial parameter from 30 per cent vacancy to 50 per cent, so that a 'ghost estate' was defined as ten or more housing units where at least a half of these were unoccupied or still under construction. We felt it would be difficult to argue that a housing scheme where half the properties were unoccupied/under construction did not constitute a 'ghost estate' in the popular understanding of the term. Of course, this excluded a significant number of other unfinished estates, but we wanted to head off criticism solely around the parameters that vested property interests had used to try and undermine our other analysis (such parameters then were contingent and relationally set within the specific context of an emerging discourse). The mapping revealed that there were 621 'ghost estates' in the country, ranging in size from 10 to 290 units.

On Tuesday 26 January 2010 a modified version of the mapping, wherein we classified the 'ghost estates' by size (Figure 2), was published on the IrelandAfterNAMA blog and made available to the media as a JPG file through the university's communications office. ${ }^{8}$ This was taken and then redrawn by the Associated Press (AP) as a simplified choropleth map that revealed more clearly the number of 'ghost estates' per local authority and it appeared in several newspapers on Wednesday 27 January (see Figure 3). For the AP it was clearly important to make it apparent to readers where in the country the problem was most acute. We had advised the journalist that rather than mapping raw numbers per county it would be better to standardise the findings by the number of households per county in order to reveal the extent of the issue with respect to population. The designer decided, however, to plot the total number of estates per county on the mapping and to provide an accompanying graph with the standardised rates. The NIRSA 


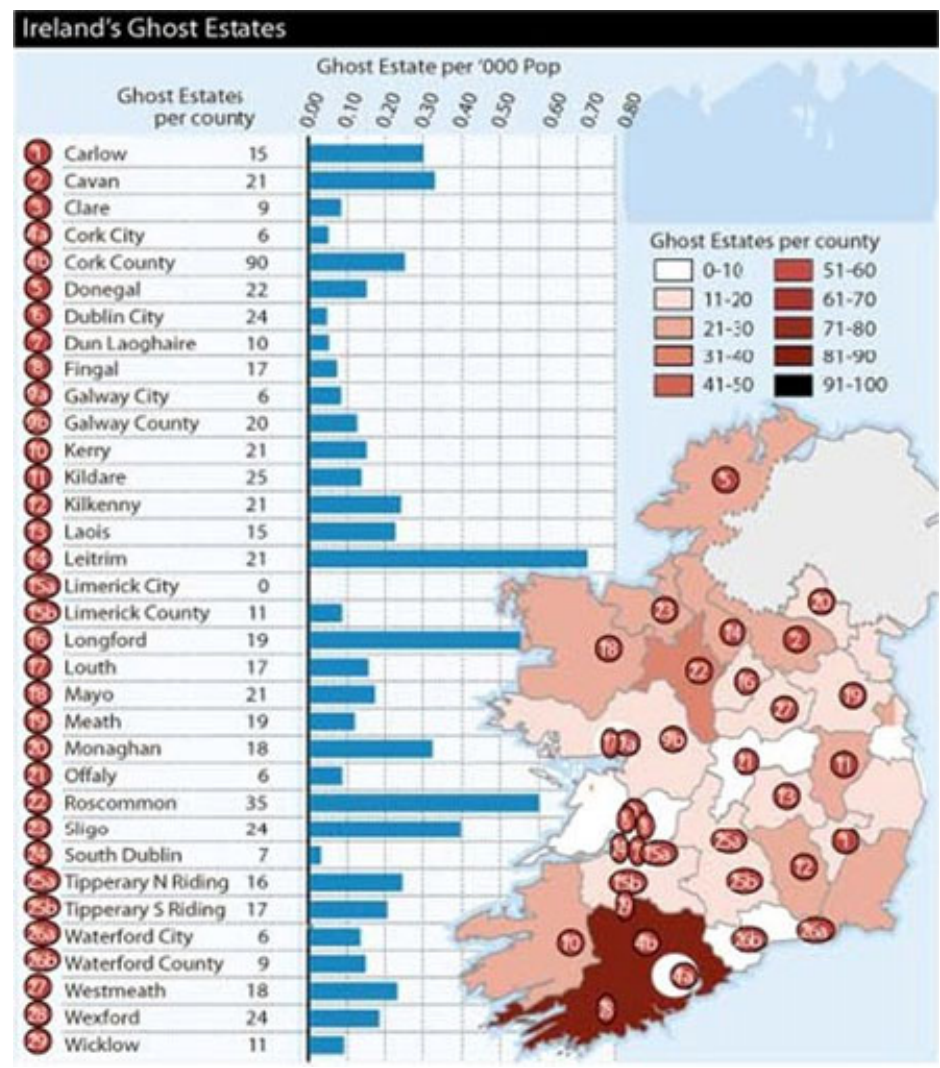

Figure 3 'Ghost estates' in Ireland Source: Associated Press

and AP mappings were important interventions in the growing public debate because they revealed for the first time the geography of the 'ghost estates' phenomenon. Whilst 'ghost estates' were shown to be a nationwide problem, affecting the major cities as well as rural areas, it was also apparent that some parts of the country were much more adversely affected than others, especially those in the Upper Shannon Rural Renewal Scheme area (the counties of Cavan, Longford, Leitrim, Roscommon and Sligo) where speculative housing development had been incentivised by tax breaks (Kitchin et al. 2010).

It was at this point that the story took off, with dozens of radio stations and local newspapers contacting the institute looking to discuss the 'ghost estate' phenomena both at a national scale and in their local area (see Figure 4) directly informed by the mapping. The lead author undertook a number of interviews where the NIRSA mapping and the method used to construct it were discussed in detail, with the mappings actively shaping the unfolding discourse. The university very quickly had to put a media strategy in place, which principally consisted of the first author only appearing on national media. At this time,
NIRSA received a number of abusive phone calls from builders, developers and estate agents, and had to negotiate other issues (such as the fact that we had published the mapping without seeking formal permission from the data licence holder; and the data were, in some senses, being used to berate agencies that we were working with on other projects and from whom the institute receives research funding). Local authorities who were revealed to have a heightened problem with 'ghost estates' moved to counter the negative criticism they were receiving from local residents as well as the media, challenging the research and our analysis in local and national media. A handful of local authorities even sought to claim they had no such unfinished housing schemes, rejecting the term 'ghost estate', despite the material evidence that they clearly had estates with high levels of vacancy and under-construction properties.

As a result of the intensity of media interest and abusive calls, and conscious that some of the press was consistently misreporting key aspects of our analysis, especially with respect to housing vacancy estimates (rather than the 'ghost estate' mapping), and that the coverage was probably not serving us 

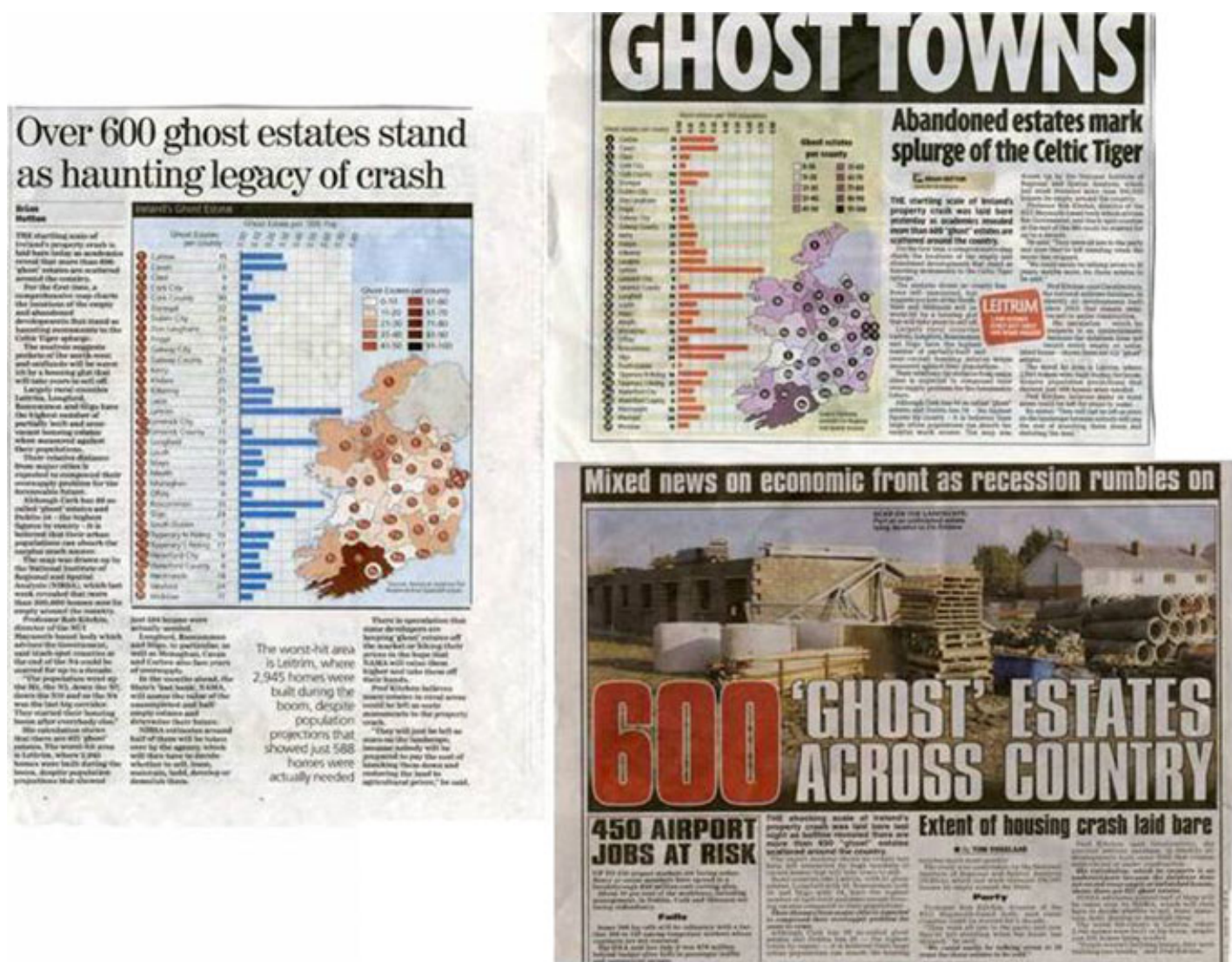

Figure 4 Sample of media coverage of the 'ghost estate' map (The Independent, The Irish Mirror, The Irish Star) Source: Mirrorpix, Associated Press

well vis-à-vis our funders, we paused blog posting on housing issues for several weeks, although the first author continued to do relevant national media work. The story re-emerged again in late March 2010 when another Irish university independently replicated our vacancy estimate results, with their study also covered extensively in the media (see Williams et al. 2010). This second study was important because it verified and legitimated our analysis. Moreover, by this time, much of the public debate had shifted onto what to do about 'ghost estates' in terms of alternative uses and the significant issues that people living on them face (e.g. service provision, health and safety, security, anti-social behaviour and negative equity). Not long afterwards, the Irish government announced that it was going to undertake a comprehensive survey of all unfinished housing estates in the country in order to determine the full extent of the issue.

In the meantime, NIRSA continued to research the issues relating to the property crisis, seeking to explain the phenomenon and its geography. In essence, what we were doing was producing a detailed epimapping to accompany and justify our research findings and mappings, and it is instructive to note that at no point did the mappings work independently of a supporting discursive apparatus of text, other visualisations such as statistical graphs, and interviews. In other words, it is important to appreciate that academic mappings work in conjunction with a range of discursive forms. And they are not always the end point of a piece of an analysis, but a conduit through which to move on to new, complementary research and disseminate findings. We had told journalists early in 2010 that NIRSA was working on a comprehensive overview report that drew together and extended our blog posts, so it was important for the institute's reputation to complete and publish it in a timely fashion.

In order to extend the analysis we co-opted two new academic co-authors with a knowledge of planning and property development in Ireland. The subsequent report went through numerous iterations as we sought to hone its content and argument and we were due to release it at the beginning of July 2010, with 
several journalists seeking an exclusive to publish the findings. After discussions with the university's press office and PR company, we decided to go with an offer from Prime Time, Ireland's leading investigative current affairs television programme, who were offering to make a short documentary based on the report with major editorial control held by NIRSA. Filming took place during mid-July and the programme was broadcast on 29 July, with the report being published on the same day (Kitchin et al. 2010). In the following days, the report's findings, including the distribution of 'ghost estates' as revealed by the mapping, were discussed multiple times in newspapers (including being the main editorial comment in the three main broadsheets) and on radio and television, and we did a number of interviews.

In October 2010 the Department of Environment, Community and Local Government released the results of its housing survey, which revealed that there were 2846 such unfinished estates across the country and provided information on the conditions of the properties and associated services (some 777 of these housing schemes met the criteria of 'ghost estate' as defined by our initial study). The DECLG produced a mapping for the country as a whole (Figure 5) and for every local authority, and several derivative mappings appeared in the national newspapers. Again, we did a number of media interviews to discuss the study.

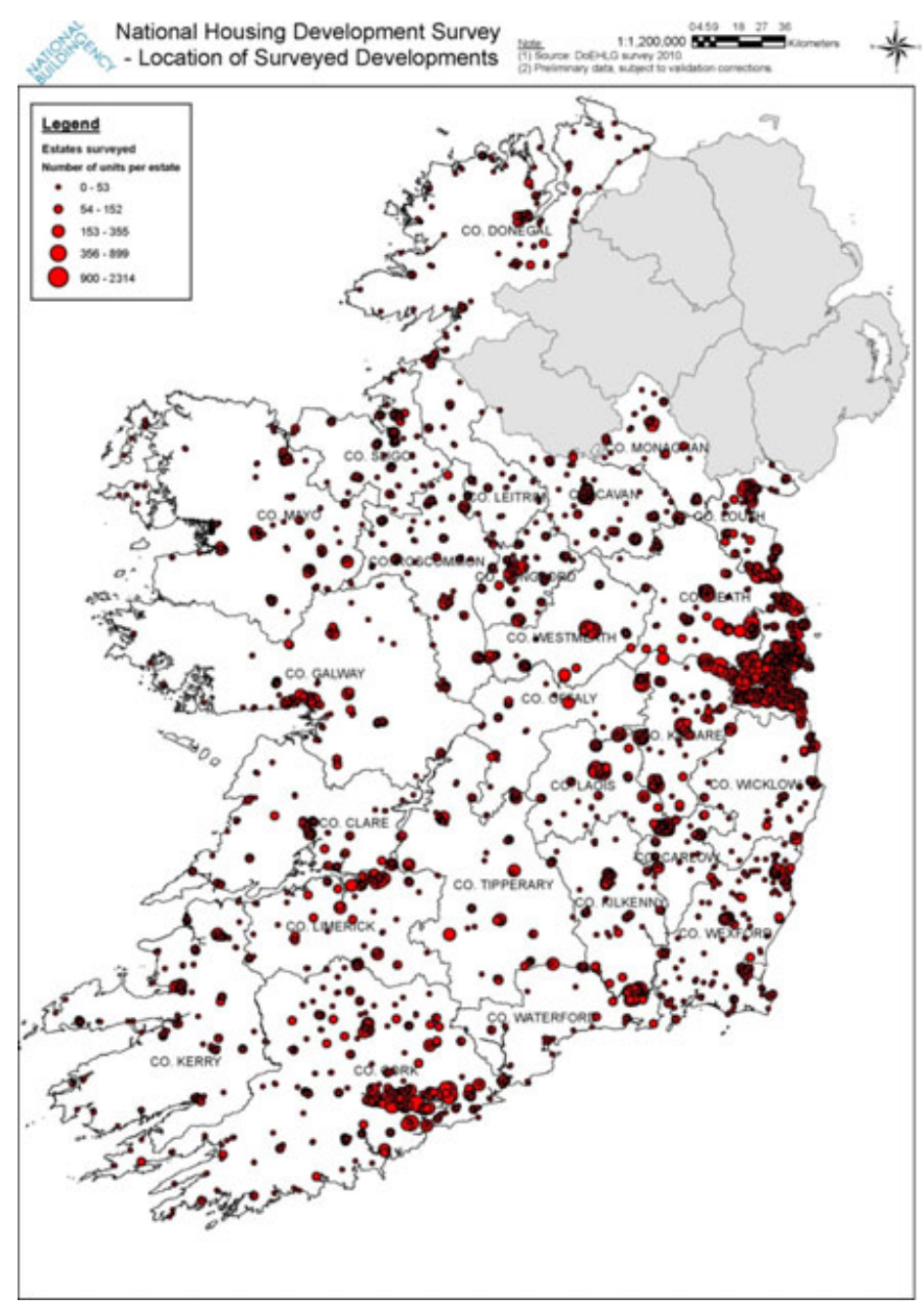

Figure 5 National Housing Development Survey - location of unfinished estates

Source: http://www.housing.ie/Our-Services/Unfinished-Housing-Developments/Survey-of-Unfinished-HousingDevelopments/2010-Survey/2010-National-Map_Location-of-Surveyed-Development.aspx (Accessed 31 May 2012) 


\section{Multiple, diverse mappings}

We subsequently took the unfinished estates data, along with other housing data made available on the Department of Environment, Community and Local Government website, and structured them into two new online interactive housing mapping modules on the All-Island Research Observatory (AIRO) website (another NIRSA 'public geography' project and official data visualisation partner of Census 2011; see Figure 6). The first of these modules enables the interactive mapping of housing and planning data from 2000 onwards, with data displayed in time-series at county level. The second plots all of the 2846 unfinished estates and enables users to query every estate with respect to a number of variables relating to occupancy, completeness, housing type, services, outstanding planning permissions, and so on. A third mapping module, developed with the Northern Ireland Housing Executive, provides housing data on an all-island basis (this involved significant data reclassification to enable it to match between jurisdictions). A fourth module has been developed in partnership with Daft.ie (operators of the largest property sales website in Ireland) to create the first subnational level house and rental price mappings. These multiple systems inherently provide diverse, unfolding mappings as what data are displayed, their scale, framing, colour scheme, and so on are to some degree directly in the control of the user (though shaped by the software's parameters). AIRO's mapping modules are routinely being used by public agencies to produce their own mappings of housing in Ireland, each of which unfolds in a contingent, relational and contextual manner to inscribe the world in often banal, mundane and subtle ways.

From the genesis of the 'ghost estates' mapping in December 2009 up to the end of 2011, NIRSA's unfolding programme of research on the phenomenon has been directly covered over 300 times in the Irish and international media, including two substantive television documentaries, an hour-long debate on national television, five other television appearances, 39 radio appearances in Ireland and abroad, 240 newspaper articles, and aggregation on over 30 wire services. It also regularly formed the backdrop to other radio discussion and newspaper pieces where we are not directly cited, as well as being extensively discussed in online forums, and in homes and pubs across Ireland. We have also presented and discussed various mappings, and our analysis and interpretation of them, to different organisations, including Engineers Ireland, the Architectural Association of Ireland, the Irish Planning Institute, and county managers and regional authority directors.

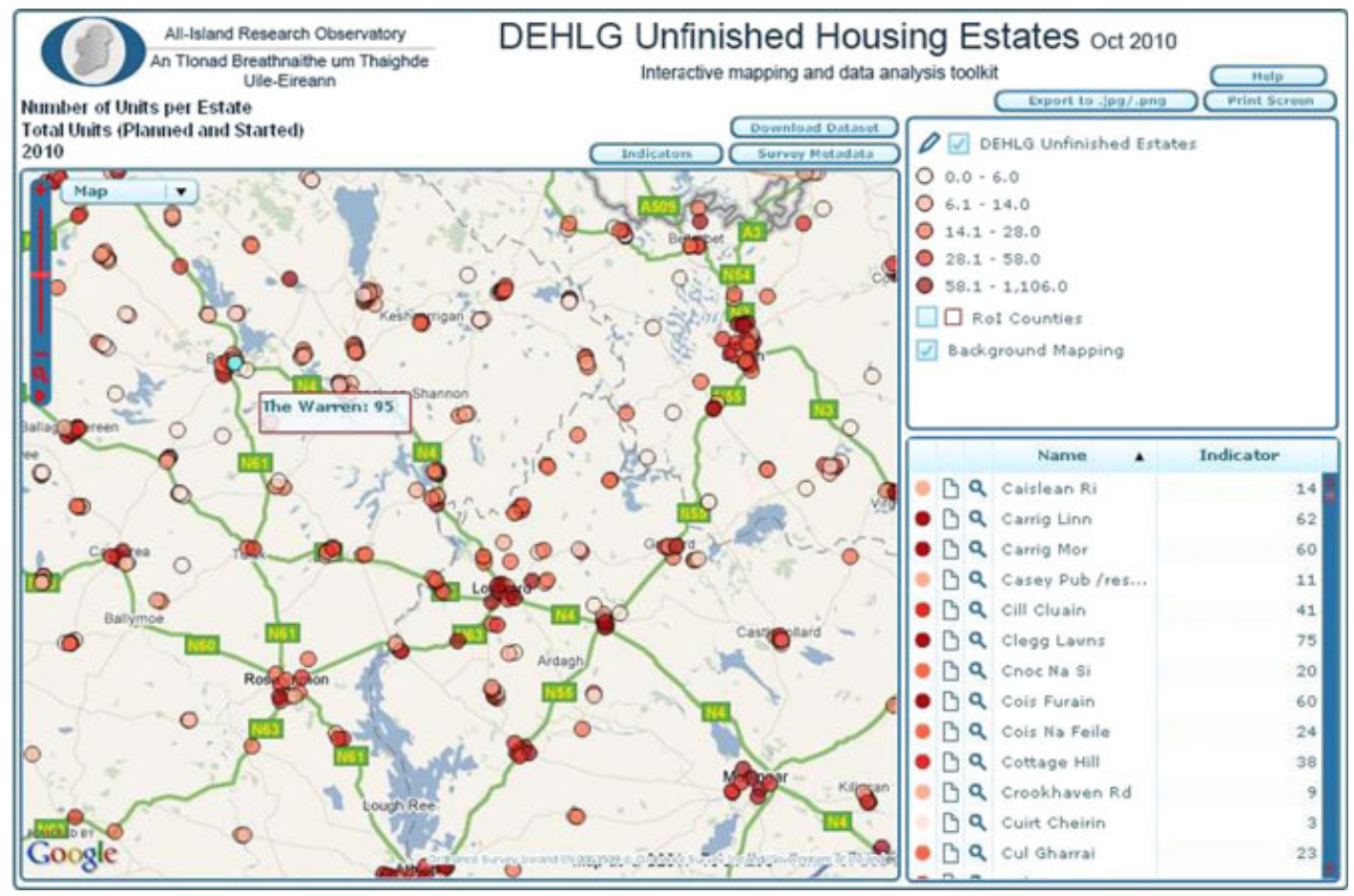

Figure 6 AIRO unfinished estates mapping module

Source: www.airo.ie (Accessed 31 May 2012) 


\section{Conclusion}

In recent years, a small number of scholars have started to rethink the ontological foundations of cartography, moving from a representational to a processual understanding of maps, from ontology (what things are) to ontogenetic (how things become). In this paper, we have sought to complement these arguments by reconsidering the epistemology of cartography, shifting the focus of analysis from approaches that prioritise optimal ('scientific') map design and techniques of map construction, or focus on deconstructing the ideological meaning or processes of inscription or proscription, to those that concentrate on how mappings unfold through a plethora of contingent, relational and contextual practices and do diverse work in the world through discursive events and material sites in conjunction with other modes of communication (such as text, images, spoken word, interactive new media) and forms of practice (such as collaboration, presentation, publication, debate). Indeed, it is important to appreciate that mappings rarely unfold in isolation, but are embedded within wider discursive fields (such as government reports, blog posts, academic papers, newspaper articles, etc.) and forms of praxis (navigating, studying, interpreting, claiming, etc.).

Operationalising such an epistemology can be achieved through a diverse set of methods including genealogies, ethnographies, ethnomethodology, participant observation, observant participation and deconstruction - that are sensitive to capturing and distilling the unfolding and contextual practices of mapping; how mappings are (re)produced through discursive and material practices shaped by personal, social, embodied, political and economic relations; how the sites in which they are embedded matters to their form; how they contextually operate with respect to other discursive media and modes of praxis; and how they perform as actants in the world shaping knowledge and actions. We have noted how such methods have been employed in a range of other studies and also provided a detailed case example of mappings of 'ghost estates' in Ireland by constructing through observant participation a genealogy of the unfolding life of a set of mappings and their subsequent work in the world in terms of shaping public debate and public policy.

What our example amply demonstrates is that mappings are beckoned into being and do work in the world in thoroughly contingent ways through complex networks of knowledge, discourse, media forms, technologies and networks of power and patronage. The research was framed within personal and professional concerns that shifted and evolved over time in reaction to circumstance and what was happening in the univer- sity and within the wider public sphere in Ireland. The mappings themselves were produced through a negotiated, reflexive, collaborative process, emerging through several iterations, framed with the emerging public debate surrounding NIRSA's analysis of the housing crisis in Ireland. On formal publication the mappings then took on a new life as the media, state and public remade and reterritorialised the information, putting the mapping to work in diverse ways, generating significant public discourse around 'ghost estates', their geography, the reasons why they exist, the issues affecting people living on them, their effects on the wider housing market and ensuing fiscal crisis, and what to do about them. The 'power of the mapping' (Wood 1992) then was not in the privilege of the authors, nor did it have a teleological inevitability. Instead, its relational power to make a difference was negotiated and debated - evoked, challenged, denied, re-asserted - pushed and pulled through a series of media lens and public debates, bound within a contingent set of emergent social, political and economic relations, embedded in specific sites (computer labs, ministerial offices, pubs, television studios, etc.). And the unfolding public reaction to the work led to further research and new mappings, whilst the original mappings continued to have diverse effects in the world beyond the cartographers' control.

In this sense, NIRSA's 'ghost estate' mappings did not simply represent territory; in a very real sense they also worked to produce it (Pickles 2004). The mappings opened up new ways of understanding the property crash in Ireland, some possibilities for addressing the issue, and have led to new discourses and programmes that flowered and took on a life far beyond and out of control of our original intentions or expectations. The mappings and the associated discursive and material unfolding that bloomed around them then contributed to varying extents to the emerging geoscape of housing in Ireland:

a shifting landscape comprised of image-maps, projections and plans, irredentist land claims, borders and jurisdictions, strata and striations, imagined worlds, projected homes and homelands, addressing systems, and various terra incognita. (Bratton 2009, 333)

By rethinking the ontological basis of cartography and reconsidering the epistemological approaches to cartographic scholarship, geographers and allied social scientists can start to get a much better understanding of how mappings emerge into existence and chart in much richer ways how they co-constitutively produce evolving geoscapes.

\section{Acknowledgements}

The authors would like to thank the three anonymous referees and the editor for their constructive 
comments on earlier drafts of this paper. The research reported was in part funded by Cycle 4 of the Programme for Third Level Institutions administered by the Higher Education Authority, Ireland.

\section{Notes}

1 See Kitchin et al. (2009) for a fuller review of the development of recent conceptual thought with respect to ontology in cartography.

2 Available at http://www.jchs.harvard.edu/research/publi cations/state-nation\%E2\%80\%99s-housing-2011 (Accessed 31 May 2012).

3 The blog is http://irelandafternama.wordpress.com and, as of May 2012, it had received over 317000 unique visits, with 278 subscribers including a number of journalists (Accessed 31 May 2012).

4 See http://irelandafternama.wordpress.com/2010/01/12/ identifying-under-construction-ghost-estates/ (Accessed 31 May 2012).

5 The vacancy rate in the April 2006 census had been 217000 houses (not including holiday homes), about 12 per cent of total stock. There have been no official statistics since, and yet we knew that over 248000 houses had been built between January 2006 and December 2009 (DECLG 2010).

6 See http://irelandafternama.wordpress.com/2010/01/18/anestimate-of-vacant-housing-in-ireland/ (Accessed 31 May 2012).

7 The DECLG (produced by DKM 2009) and NIRSA estimated three measures: vacancy, including holiday homes (DKM: 301 682-326 685; NIRSA: 338 031); vacancy, excluding holiday homes (DKM: 228 206-253 209; NIRSA: 252029 ); and potential oversupply (DKM 122 029-147 032; NIRSA 120 248).

8 See http://irelandafternama.wordpress.com/2010/01/25/ identifying-ireland's-ghost-estates/ (Accessed 31 May 2012).

\section{References}

Bratton B H 2009 On geoscapes and Google caliphate Theory, Culture and Society 26 329-42

Brown B and Laurier E 2005a Maps and journeys: An ethno-methodological investigation Cartographica 40 17-33

Brown B and Laurier E 2005b Designing electronic maps: an ethnographic approach in Meng L, Zipf A and Reichenbacher $\mathbf{T}$ eds Map-based mobile services: theories, methods and implementations Berlin, Springer 241-57

Brown M and Knopp L 2008 Queering the map: the productive tensions of colliding epistemologies Annals of the Association of American Geographers 98 40-58

Burman C and MacLure M 2005 Deconstruction as a method of research in Somekh B and Lewin C eds Research methods in the social sciences Sage, London 284-92

Central Bank 2011 Residential mortgage arrears and repossession statistics Irish Central Bank, Dublin (http://www.cen tralbank.ie/press-area/press-releases/Documents/Press $\% 20$ Release \%20Table\%20and\%20Notes\%20-\%20Sept\%202011. pdf) Accessed 31 May 2012

Crampton J W 2003 The political mapping of cyberspace Edinburgh University Press, Edinburgh
Crang M and Cook I 2007 Doing ethnographies Sage, London

Crowley U 2009 Genealogy method in Kitchin R and Thrift $\mathbf{N}$ eds International encyclopedia of human geography Elsevier, Oxford vol 4 341-44

CSO 2011a Census 2011 preliminary results Central Statistics Office, Dublin (http://www.cso.ie/en/media/csoie/census/ documents/Prelim\%20complete.pdf) Accessed 31 May 2012

CSO 2011b Residential property price index Central Statistics Office, Dublin (http://www.cso.ie/en/media/csoie/releases publications/documents/prices/2011/rppi_dec2011.pdf) Accessed 31 May 2012

CSO 2011c Live register Central Statistics Office, Dublin (http://www.cso.ie/en/media/csoie/releasespublications/docu ments/labourmarket/2011/lreg_nov2011.pdf) Accessed 31 May 2012

CSO 2011d National income (current market prices) Central Statistics Office, Dublin (http://www.cso.ie/en/statistics/ nationalaccounts/principalstatistics/nationalincomecurrent marketpricesm/) Accessed 31 May 2012

Del Casino V J and Hanna S P 2006 Beyond the 'binaries': a methodological intervention for interrogating maps as representational practices ACME: An International E-Journal for Critical Geographies 4 34-56

della Dora V 2009 Performative atlases: memory, materiality and (co-)authorship Cartographica 44 240-55

DECLG 2010 Housing statistics Department of Environment, Community and Local Government, Dublin (http://www. environ.ie/en/Publications/StatisticsandRegularPublications/ HousingStatistics/) Accessed 31 May 2012

DKM 2009 Review of the construction industry 2008 and outlook 2009-2011 DKM Economic Consultants Ltd, Dublin (http://www.environ.ie/en/Publications/StatisticsandRegular Publications/ConstructionIndustryStatistics/FileDownLoad, 21120,en.pdf) Accessed 31 May 2012

Dodge M, Kitchin R and Perkins C 2011 The map reader Wiley-Blackwell, Oxford

Edney M H 1993 Cartography without 'progress': reinterpreting the nature and historical development of map-making Cartographica 30 54-68

Gregory D 2010 Seeing red: Baghdad and the event-ful city Political Geography 29 266-79

Harley J B 1989 Deconstructing the map Cartographica 26 $1-20$

Herbert S 2000 For ethnography Progress in Human Geography 24 550-68

Honohan P 2010 The Irish banking crisis: regulatory and financial stability policy 2003-2008 Irish Central Bank, Dublin

Ingold T 2010 Bringing things to life: creative entanglements in a world of materials NCRM working paper 05/10 (http://eprints.ncrm.ac.uk/1306/1/0510_creative_entangle ments.pdf) Accessed 31 May 2012

Kitchin R 2008 The practices of mapping Cartographica 43 211-15

Kitchin R and Dodge M 2007 Rethinking maps Progress in Human Geography 31 331-44

Kitchin R, Gleeson J, Keaveney K and O'Callaghan C 2010 A haunted landscape: housing and ghost estates in post-Celtic Tiger Ireland NIRSA working paper 59 
(http://www.nuim.ie/nirsa/research/documents/WP59-AHauntedLandscape.pdf) Accessed 31 May 2012

Kitchin R, Perkins C and Dodge M 2009 Thinking about maps in Dodge $\mathbf{M}$, Kitchin $\mathbf{R}$ and Perkins $\mathbf{C}$ eds Rethinking maps Routledge, London 1-25

Kitchin R, O'Callaghan C, Boyle M, Gleeson $J$ and Keaveney K 2012 Placing neoliberalism: the rise and fall of Ireland's Celtic Tiger Environment and Planning $A 44$ 1302-26

Latour B 1987 Science in action Harvard University Press, Cambridge MA

Morton F 2005 Performing ethnography: Irish traditional music sessions and new methodological spaces Social and Cultural Geography 6 661-76

Pickles J 2004 A history of spaces: cartographic reason, mapping and the geo-coded world Routledge, London

Robinson A H 1952 The look of maps University of Wisconsin Press, Madison WI
Robinson A H, Morrison J L, Muehrcke P C, Kimerling A J and Guptill S C 1995 Elements of cartography 6th edn John Wiley and Sons, New York

Savills 2010 Savills Dublin office market in minutes Q2 2010 Savills, Dublin (http://www.savills.ie/pdfs/market_watch/ dublin-office-market-in-minutes-q2-2010.pdf) Accessed 31 May 2012

The Sunday Times 2010 Residents stranded on ghost estates The Sunday Times 17 January, 19

Williams B, Hughes B and Redmond D 2010 Managing an unstable housing market UCD Urban Institute Ireland Working paper series UII 10/02 (http://www.uep.ie/pdfs/ WP\%201002\%20W.pdf) Accessed 31 May 2012

Wood D 1992 The power of maps Guilford Press, New York

Wood D 2010 Rethinking the power of maps Guildford Press, New York

Wood D and Fels J 2008 The natures of maps Chicago University Press, Chicago IL 